\title{
ANALISIS PERUBAHAN PERILAKU DAN USAHA DALAM KAJI TERAP GOOD FARMING PRACTICES DAN APLIKASI SIDIK DI KECAMATAN PANJALU KABUPATEN CIAMIS
}

\section{ANALYSIS OF CHANGES IN BEHAVIOR AND BUSINESS IN THE APPLICATION OF GOOD FARMING PRACTICES AND SIDIK APPLICATIONS IN PANJALU DISTRICT CIAMIS REGENCY}

\author{
Aldi Prayoga ${ }^{1 *}$, Wardani ${ }^{1}$, Arif Nindyo Kisworo ${ }^{1}$ \\ ${ }^{1}$ Politeknik Pembangunan Pertanian Bogor \\ *Email: aldiprayoga556@gmail.com
}

\begin{abstract}
The supply of beef cattle and beef in the country has been based on smallholder farms around $97.7 \%$. The growth of domestic beef production (supply) during 2005-2013 continues to increase, but has not been able to keep up with the pace of demand so imports are needed. Therefore, it is necessary to have an intensive beef cattle maintenance system through good beef cattle fattening agribusiness (good farming practice). Based on this background, the objectives to be achieved are: 1). Identify the level of change in knowledge, attitudes and skills of farmers. 2). To identify the effect of using the Animal Husbandry SIDIK application in beef cattle maintenance management on the income of farmers. The research method used is the interview method through a structured questionnaire from 30 respondents. The data analysis method used extension analysis (Padmowihardjo formula, 1999), and business analysis (calculation of income level). The applied study was carried out for 40 days at the Gentra Pusaka Tunas Muda Farmer Group, which consisted of 3 treatments, namely control (P0) of traditional cattle fattening. The second treatment $(\mathrm{P} 1)$ was fattening cattle with GFP. While the third treatment $(\mathrm{P} 2)$ is that farmers apply GFP + Livestock Imprint Application. Evaluation of the implementation of the extension obtained the results: There was a change in knowledge of $(39.58 \%=$ quite successful), skills $(37.39 \%=$ quite successful $)$, and attitudes $(41.39 \%=$ quite successful). Business analysis obtained results $\mathrm{P} 0=\mathrm{Rp} \cdot 1.214 .400 .00, \mathrm{P} 1=\mathrm{Rp} \cdot 1.376 .600 .00$, and $\mathrm{P} 2=\mathrm{Rp} \cdot 1.571 .000,00$. It can be concluded that the application of GFP and Livestock Print Applications can be recommended for beef cattle fattening efforts.
\end{abstract}

Keywords: beef cattle fattening, good farming practices, SIDIK Application

\begin{abstract}
ABSTRAK
Penyediaan sapi potong dan daging sapi dalam negeri selama ini $97,7 \%$ berbasis peternakan rakyat. Pertumbuhan produksi daging sapi (supply) dalam negeri selama 2005-2013 terus meningkat, namun belum mampu mengimbangi laju permintaan (demand) sehingga diperlukan impor. Oleh karenanya perlu adanya sistem pemeliharaan sapi potong secara intensif melalui agribisnis penggemukan sapi potong yang baik (good farming practice). Berdasarkan latar belakang tersebut, maka tujuan yang hendak dicapai ialah : 1). Mengidentifikasi tingkat perubahan pengetahuan, sikap dan keterampilan peternak. 2). Menganalisis usaha tani dalam kaji terap GFP dan aplikasi. Metode penelitian yang digunakan yaitu metode kuantitatif dengan cara pengambilan data melalui metode wawancara melalui kuesioner terstruktur dari 30 responden. analisis data menggunakan analisis penyuluhan (rumus Padmowihardjo,1999), dan analisis Usaha (perhitungan tingkat pendapatan). Kaji terap dilaksanakan selama 40 hari di Kelompoktani Gentra Pusaka Tunas Muda, yang terdiri dari 3 perlakuan yaitu kontrol (P0) penggemukan sapi secara tradisional. Perlakuan kedua (P1) penggemukan sapi dengan GFP. Sedangkan perlakuan ketiga (P2) yakni peternak menerapkan GFP + Aplikasi Sidik Peternakan. Evaluasi pelaksanaan penyuluhan diperoleh hasil : Terjadi perubahan pengetahuan sebesar cukup berhasil 39,58 \%, keterampilan cukup berhasil 37,39 \%, dan sikap cukup berhasil 41,39\%. Analisis Usaha diperoleh hasil P0 = Rp.1.214.400,00, P1 = Rp.1.376.600,00, dan P2 = Rp.1.571.000,00. Dapat disimpulkan penerapan GFP dan Aplikasi Sidik Peternakan dapat direkomendasikan untuk usaha penggemukan sapi potong.
\end{abstract}

Kata Kunci: aplikasi Sidik, penggemukan sapi potong, good farming practice 


\section{PENDAHULUAN}

Peternakan merupakan subsektor yang sangat penting, diantaranya dalam hal peningkatan sumberdaya manusia melalui penyediaan pangan hewani yang berkualitas, disamping itu dalam bidang ekonomi sektor pertanian memiliki peranan strategis dalam pembangunan nasional. Seiring berjalannya waktu dengan semakin besarnya jumlah penduduk, pemahaman masyarakat akan pentingnya konsumsi makanan bergizi serta berkembangnya gaya hidup yang semakin tinggi. Hal ini berakibat terhadap permintaan produk peternakan yang semakin tinggi pula. Ini menunjukkan bahwa kedepan usaha sektor peternakan adalah usaha yang menjanjikan dan memiliki peluang usaha yang sangat potensial.

Sapi adalah hewan ternak terpenting dari jenis-jenis hewan ternak yang dipelihara manusia sebagai sumber daging, susu, tenaga kerja, dan kebutuhan manusia lainnya. Ternak sapi menghasilkan sekitar $50 \%$ kebutuhan daging di dunia, 95\% kebutuhan susu, dan kulitnya menghasilkan 85\% kebutuhan kulit untuk sepatu. Sapi adalah salah satu genus dari Bovidae. Ternak atau hewan-hewan lainnya yang termasuk famili ini ialah bison, banteng (Bibos), kerbau (Bubalus), kerbau afrika (Syncherus), dan anoa (Pane 1993).

Berdasarkan data dari Badan Pusat Statistik (BPS) 2019, penyediaan sapi potong dan daging sapi dalam negeri selama ini $60 \%$ berbasis peternakan rakyat. Pertumbuhan produksi daging sapi (supply) di dalam negeri dari tahun 2015-2016 terus meningkat, namun belum mampu mengimbangi laju permintaan (demand) yang semakin meningkat, sehingga untuk memenuhi permintaan tersebut diperlukan impor. Kebutuhan daging sapi secara nasional pada tahun 2016 sebesar 518 ribu ton, untuk penyediaannya dipenuhi dari produksi dalam negeri $(69,67 \%)$ dan impor $(30,33 \%)$. Impor daging sapi pada tahun
2016 cenderung naik bila dibandingkan dengan tahun sebelumnya yakni sebanyak 160 ribu ton dan berdasarkan angka sementara realisasi impor tahun 2019 yaitu bulan Mei sudah mencapai 73,5 ribu ton.

Dalam peningkatan produksi daging sapi secara optimal perlu adanya sistem pemeliharaan sapi potong secara intensif melalui agribisnis penggemukan sapi potong yang baik (good farming practice). Good Farming Practice (GFP) merupakan cara beternak yang baik dan benar, yang memperhatikan lingkungan dan memenuhi standar minimal sanitasi dan kesejahteraan ternak. GFP juga termasuk di dalamnya aturan yang berlaku di lingkungan, hygiene atau sanitasi, kesejahteraan ternak, identifikasi, registrasi ternak, serta kesehatan ternak (DAFRD 2001).

Aspek-aspek utama dalam GFP yaitu manajemen nutrisi, manajemen lahan rumput, perlindungan sungai dan sumber air, pemeliharaan habitat liar, pemeliharaan batas peternakan, penggunaan pestisida dan bahan kimia yang berhati-hati, perlindungan situssitus bersejarah, pemeliharaan penampakan visual peternakan dan lingkungannya, pemeliharaan catatan peternakan, kesejahteraan ternak, hygiene atau sanitasi, tidak menggunakan bahan yang dilarang, penggunaan obat hewan yang bertanggung jawab dan pengetahuan peternak tentang GFP. Ruang lingkup pedoman budidaya ternak sapi potong yang baik meliputi sarana, proses produksi, pelestarian lingkungan dan pengawasan (Ditjen PKH 2016).

Kecamatan Panjalu merupakan salah satu kecamatan yang terdapat di Kabupaten Ciamis Provinsi Jawa Barat yang memiliki luas wilayah 5.063,067 ha. Kecamatan Panjalu terletak di bagian Utara Kabupaten Ciamis yang berjarak $40 \mathrm{~km}$ dari Ibu Kota Kabupaten, meliputi 8 (delapan) desa. Batas wilayah Kecamatan Panjalu sebelah Timur berbatasan dengan Desa Rawa Kecamatan Lumbung, sebelah Barat berbatasan dengan Desa Banjarangsana 
Kecamatan Panumbangan, sebelah Utara berbatasan dengan Desa Cibeureum Kecamatan Sukamantri, sedangkan sebelah Selatan dibatasi oleh Gunung Syawal. Dengan jumlah ternak sapi sebanyak 812 ekor dan produksi daging sapi sebesar $120.900 \mathrm{~kg}$ pada tahun 2019. Usaha peternakan di Kecamatan Panjalu cukup potensial walaupun bukan merupakan usaha pokok. Faktor lingkungan sangat mendukung dalam kegiatan usaha peternakan sapi dimana tersedianya pakan untuk ternak tersebut. Faktor lingkungan tersebut yaitu didukung dengan keadaan topografi yang terdiri atas pedataran dan pegunungan dengan ketinggian 700-800 mdpl dan jumlah penduduk sebanyak 50.457 orang (BPP 2020).

Berdasarkan kajian hasil survei sebagian besar peternak sapi di Kecamatan Panjalu masih melaksanakan teknis pengggemukan sapi secara tradisional dengan belum memperhatikan manajemen pemeliharaan sapi yang baik yakni belum adanya kebiasaan peternak dalam pencatatan usaha peternakan sapi potong. Namun jika dianalisis dalam kehidupan masyarakat di Kecamatan Panjalu sangat masif dalam penggunaan alat komunikasi ponsel android untuk sehari-harinya tidak terkecuali para peternak. Oleh karena itu berdasarkan latar bakang tersebut penulis mengangkat judul yakni "Analisis Perubahan Perilaku dan Usaha Dalam Kaji Terap Good Farming Practices dan Aplikasi Sidik di Kecamatan Panjalu Kabupaten Ciamis ". Tujuan yang akan dicapai dalam penelitian ini adalah : 1). Mengidentifikasi tingkat perubahan pengetahuan, sikap dan keterampilan peternak dalam sistem agribisnis penggemukan sapi potong. 2). Menganalisis usaha tani dalam kaji terap GFP dan aplikasi Sidik.

\section{METODE}

Penelitian dilaksanakan pada April 2021 di Dusun Baros Desa Ciomas
Kecamatan Panjalu Kabupaten Ciamis. Materi yang diberikan pada kegiatan penyuluhan adalah penerapan GFP pada agribisnis penggemukan sapi potong melalui penggunaan aplikasi Sidik (Sistem Identifikasi dan Recording Ternak) berbasis android ponsel di Kelompoktani Gentra Tunas Muda.

Materi GFP yang telah diberikan dalam penyuluhan terdiri dari:

a) pola pemeliharaan penggemukan sapi potong di Kelompoktani Gentra Pusaka Tunas Muda dijalankan secara intensif atau kereman yakni sapi potong dipelihara dalam kandang dari awal kedatangan sapi bakalan sapi masa panen tiba;

b) kesehatan dan kesejahteraan hewan. Materi aspek kesehatan yakni seputar manajemen kesehatan hewan (pemberian obat cacing tiap tiga bulan sekali, pemberian vitamin B Compleks, dan antibiotic. Kesejahteraan hewan diberikan materi seputar lima prinsip animal walfare: 1) freedom from hunger and thirst atau bebas dari rasa lapar dan haus, 2) freedom from discomfort atau bebas dari rasa panas dan tidak nyaman, 3) freedom from pain, injury, and disease atau bebas dari luka, penyakit \& sakit, 4) freedom from fear and distress atau bebas dari rasa takut dan penderitaan, dan 5) freedom to express normal behavior dan bebas mengekspresikan perilaku normal dan alamiahnya);

c) manajemen rekording ternak yakni diberikan materi mengenai pentingnya manajemen pencatatan ternak dalam usaha penggemukan sapi potong dan jenis- jenisnya.

Metode yang digunakan pada penelitian ini Metode kuantitatif dengan cara pengambilan data melalui metode wawancara melalui kuesioner terstruktur dari 30 responden. Kaji terap telah dilaksanakan di Kelompok Ternak Gentra Pusaka Tunas Muda, Desa Ciomas, Kabupaten Ciamis. Kaji terap menggunakan Rancangan Acak Kelompok (RAK) dengan tiga perlakuan 
dan tiga ulangan (U1,U2,U3). Dilanjutkan dengan Analisis Sidik Ragam (One Way Anova) untuk mengetahui pengaruh penerapan GFP terhadap pertambahan bobot badan sapi. Pengumpulan data menggunakan data primer dan data skunder (kuesioner). Analisis Data, menggunakan analisis deskritif dan analisis usaha meliputi $B E P, R / C$ ratio, dan $\mathrm{B} / \mathrm{C}$ ratio.

\section{HASIL DAN PEMBAHASAN}

Kecamatan Panjalu terletak di bagian Utara Kabupaten Ciamis yang berjarak $40 \mathrm{~km}$ dari Ibu Kota Kabupaten, meliputi 8 desa. Luas wilayah Kecamatan Panjalu 5.063 ha dengan jumlah penduduk sebanyak 50.457 orang. Keadaan topografi terdiri atas pedataran dan pegunungan dengan ketinggian 700800 mdpl. Geografis wilayah Kecamatan Panjalu berada pada $108^{\circ} 27087^{\prime}$ Bujur Timur dan sampai dengan $7^{\circ} 13564$ " Lintang Selatan dengan batas-batas wilayah sebelah Timur yaitu Desa Rawa Kecamatan Lumbung, sebelah Barat yakni Desa Banjarangsana Kecamatan Panumbangan, sebelah Utara yaitu Desa Cibeureum Kecamatan Sukamantri dan sebelah Selatan ialah Gunung Syawal.

Penduduk Kecamatan Panjalu berjumlah 50.810 orang yang terdiri atas Laki-laki 25.658 orang $(50,517 \%)$, Perempuan 25.152 orang $(49,482 \%)$ dengan jumlah Kepala Keluarga (KK) yaitu 13.735 .

Sumberdaya Alam di Kecamatan Panjalu mempunyai luas lahan 5.063.037 ha, terdiri atas lahan sawah 1.270 ha $(25,08 \%)$ dan lahan kering 3.793,037 ha $(74,92 \%)$. Data usahatani di Kecamatan Panjalu diperoleh melalui beberapa petani responden dan laporan dari para penyuluh dan petugas di lapangan, tingkat desa dan hasil evaluasi kegiatan berdasarkan komoditas yangdiusahakan oleh para petani. Salah satu komoditas yang dikelola oleh pelaku utama usaha pertanian adalah tanaman pangan, yang meliputi padi, palawija, dan hortikultura.
Komoditas sub sektor peternakan yang diusahakan di Kecamatan Panjalu antara lain yaitu sapi potong (812 ekor), sapi perah (67 ekor), kambing \& domba (7.236), kerbau (69), ayam buras (18.500), ayam petelur (11.600), ayam ras pedaging (60.615), dan itik (2.600). Sedangkan jenis ternak lainnya yang hanya sebagai sambilan.

Kelembagaan penyuluhan terdiri dari pelaku utama dan usaha pertanian di Kecamatan Panjalu yaitu Kelompoktani, Gabungan Kelompoktani, Koperasi Tani, dan Asosiasi. Jumlah kelompok di Kecamatan Panjalu sebanyak 132 Kelompok. Sedangkan jumlah Gabungan Kelompoktani (Gapoktan) di Kecamatan Panjalu sebanyak 8 Gapoktan di 8 desa.

\section{ANALISIS PENYULUHAN}

Analisis penyuluhan dilaksanakan untuk mengetahui sejauh mana tingkat perubahan pengetahuan, keterampilan, dan sikap peternak dalam menerapkan GFP agribisnis penggemukan sapi potong. Perubahan tingkat pengetahuan, keterampilan, dan sikap peternak digunakan sebagai dasar untuk mengukur sejauh mana tingkat keberhasilan dalam kegiatan penyuluhan yang telah dilaksanakan. Keberhasilan penyuluhan diukur menggunakan instrumen penyuluhan yakni berupa kuesioner yang telah teruji validitas dan reliabilitasnya. Kuesioner terdiri dari pre test dan post test yang digunakan untuk mengukur skor peningkatan pengetahuan, keterampilan, dan sikap peternak dalam menerapkan GFP agribisnis penggemukan sapi potong.

Analisis awal dilaksanakan sebelum peternak mendapatkan materi penyuluhan tentang penerapan GFP agribisnis penggemukan sapi potong di Kelompoktani Gentra Pusaka Tunas Muda yang bertujuan mendapatkan data awal rekapitulasi pre test tingkat pengetahuan, keterampilan, dan sikap peternak. Adapun data hasil pre test tersebut dapat dilihatpada Tabel 1. 
Tabel 1 Rekapitulasi Hasil Pre Test Pengetahuan, Keterampilan, dan Sikap

\begin{tabular}{clccc}
\hline No & Aspek Penilaian & $\begin{array}{c}\text { Jumlah } \\
\text { Nilai }\end{array}$ & $\begin{array}{c}\text { Pre Test } \\
\text { Jumlah Nilai } \\
\text { Maksimal }\end{array}$ & $\begin{array}{c}\text { Prosentase } \\
(\%)\end{array}$ \\
\hline 1. & Pengetahuan tentang GFP & 603 & 1200 & 50,25 \\
2. & Keterampilan penerapan GFP & 171 & 360 & 47,50 \\
3. & Sikap (menerima/menolak) GFP & 138 & 360 & 38,00 \\
\hline
\end{tabular}

Sumber : data primer terolah

Analisis akhir dilaksanakan setelah peternak mendapatkan materi penyuluhan tentang penerapan GFP agribisnis penggemukan sapi potong.
Tahapan ini bertujuan untuk memperoleh data akhir rekapitulasi post test. Hasil post test tersebut dapat dilihat pada Tabel 2.

Tabel 2 Rekapitulasi Hasil Post Test Pengetahuan, Keterampilan, dan Sikap

\begin{tabular}{clccc}
\hline No & Aspek Penilaian & $\begin{array}{c}\text { Jumlah } \\
\text { Nilai }\end{array}$ & $\begin{array}{c}\text { Pre Test } \\
\text { Jumlah Nilai } \\
\text { Maksimal }\end{array}$ & $\begin{array}{c}\text { Prosentase } \\
(\%)\end{array}$ \\
\hline 1. & Pengetahuan tentang GFP & 1078 & 1200 & 89,83 \\
2. & Keterampilan penerapan GFP & 306 & 360 & 85,00 \\
3. & Sikap (menerima/menolak) GFP & 287 & 360 & 79,72 \\
\hline
\end{tabular}

Sumber : data primer terolah

\section{ASPEK PENGETAHUAN}

Hasil yang didapat bahwa jumlah nilai pre test pengetahuan responden terhadap penerapan Good farming practice (GFP) yakni 603 dengan persentase $50,25 \%$ Setelah dilakukannya penyuluhan, pengetahuan responden mengalami peningkat an dan perubahan yang signifikan. Hal tersebut dapat dilihat dari peningkatan nilai post test dengan jumlah nilai sebesar 1.078 dengan persentase 89,83\%. Hasil akhir (pre test dan post test) dari aspek pengetahuan dapat dijadikan penentuan apakah penyuluhan tersebut berhasil atau tidak. Menurut Padmowihardjo (1999), penentuan hasil penjumlahan dapat menggunakan rumus sebagai berikut :

$$
\begin{aligned}
N & =\frac{\sum \text { Nilai post test }-\sum \text { Nilai pre test }}{\text { Nilai maksimal }} \times 100 \% \\
& =\frac{1078-603}{1200} \times 100 \% \\
& =39,58 \%
\end{aligned}
$$

sehingga dari perhitungan tersebut telah dibuktikan bahwasanya terjadi peningkatan perubahan tingkat pengetahuan petani yakni sebesar $39,58 \%$ dalam kategori cukup berhasil.

\section{ASPEK KETERAMPILAN}

Hasil yang didapat bahwa jumlah nilai pre test keterampilan responden terhadap penerapan Good farming practice (GFP) yakni 171 dengan persentase $47,50 \%$ Setelah dilaksanakan penyuluhan, keterampilan responden mengalami peningkatan dan perubahan yang signifikan. Hal tersebut dapat dilihat dari peningkatan nilai post test dengan jumlah nilai sebesar 306 dengan persentase 85,00 \%. Hasil akhir (pre test dan post test) dari aspek keterampilan dapat dijadikan penentuan apakah penyuluhan tersebut berhasil atau tidak. Menurut Padmowihardjo (1999), penentuan hasil penjumlahan dapat menggunakan rumus sebagai berikut: 


$$
\begin{aligned}
N & =\frac{\sum \text { Nilai post test }-\sum \text { Nilai pre test }}{\text { Nilai maksimal }} \times 100 \% \\
& =\frac{306-171}{1200} \times 100 \% \\
& =37,39 \%
\end{aligned}
$$

sehingga dari perhitungan tersebut telah dibuktikan bahwasanya terjadi peningkatan perubahan tingkat keterampilan petani sebesar 37,39\% dalam kategori cukup berhasil.

\section{ASPEK SIKAP}

Hasil yang didapat bahwa jumlah nilai pre test sikap responden terhadap penerapan GFP yakni sebesar 314 dengan persentase $34,90 \%$. Setelah dilaksanakan penyuluhan, sikap responden mengalami peningkatan dan perubahan yang signifikan. Hal tersebut dapat dilihat dari peningkatan nilai post test dengan jumlah nilai sebesar 764 dengan persentase 106,2 \%. Hasil akhir (pre test dan post test) dari aspek sikap dapat dijadikan penentuan apakah penyuluhan tersebut berhasil atau tidak. Menurut Padmowihardjo (1999), penentuan hasil penjumlahan dapat menggunakan rumus sebagai berikut:

$$
\begin{aligned}
N & =\frac{\sum \text { Nilai post test }-\sum \text { Nilai pre test }}{\text { Nilai maksimal }} \times 100 \% \\
& =\frac{287-138}{1200} \times 100 \% \\
& =41,39 \%
\end{aligned}
$$

Sehingga dari perhitungan tersebut telah dibuktikan bahwasanya terjadi peningkatan danperubahan sikap petani yang signifikan yakni sebesar 41,39\% dengan kategori cukup berhasil.

\section{ANALISIS USAHA}

Analisis usaha dibutuhkan untuk mengetahui apakah hasil kaji terap yang dilaksanakan jika dilihat secara ekonomi dapat dirkomendasikan atau tidak kepada peternak, maka kaji terap harus dianalisis secara ekonomi untuk mengetahui perbedaan keuntungan antara perlakuan dengan control. Hasil dari analisis usaha penerapan Good Farming Practice (GFP) agribisnis penggemukan sapi potong dapat dilihat pada Tabel 3.

Tabel 3 Hasil Perhitungan Analsis Usaha

\begin{tabular}{ccccc}
\hline \multirow{2}{*}{ No } & \multirow{2}{*}{ Analisis Usaha } & \multicolumn{3}{c}{ Perlakuan } \\
& & PO & P1 & P2 \\
\cline { 3 - 5 } & & Tradisional & GFP & GFP+SIDIK \\
\hline 1. & Pendapatan (rp) & 1.214 .400 & 1.376 .600 & 1.571 .000 \\
2. & R/C ratio & 1.023 & 1.025 & 1.024 \\
3. & B/C ratio & 0,023 & 0,025 & 0,024 \\
4. & BEP harga & 58.650 & 58.516 & 58.598 \\
5. & BEP produksi & 866 & 892 & 1.082 \\
\hline
\end{tabular}

Sumber : data primer terolah

Tabel 3 menunjukkan analisis usaha dari ketiga perlakuan kaji terap, perlakuan yang lebih menguntungkan adalah perlakuan ketiga (P2) karena memberikan pendapatan yang lebih tinggi yaitu $\mathrm{Rp} \quad 1.571 .000,00$ sedangkan perlakuan dengan pendapatan tertinggi kedua yakni perlakuan kedua (P1) dengan pendapatan sebesar Rp 1.376,600,00 dan pendapatan dengan jumlah terkecil yakni perlakuan pertama (P1) sebesar Rp 1.214.400,00. Dari ketiga perlakuan terdapat selisih nilai pendapatan yakni $\mathrm{P0}$ dengan $\mathrm{P} 1$ sebesar Rp 162.200,00. Kemudian P1 dengan P2 sebesar Rp 194.400,00. Sehingga untuk rekomendasi usaha penggemukan sapi dengan keuntungan paling tinggi yaitu pada perlakuan ketiga (P2) dengan keuntungan sebesar $\mathrm{Rp} 1.571 .000,00$. 
$\mathrm{R} / \mathrm{C}$ ratio digunakan untuk mengetahui penerimaan dibandingkan dengan pengeluaran. $\mathrm{R}$./C rasio masing-masing perlakuan P0 (1.023), P1 (1.025), P2 $(1,024)$, dengan demikian masing-masing perlakuan ini berarti menguntungkan karena nilai $\mathrm{R} / \mathrm{C}$ rasio $>1$. Namun karena nilai $\mathrm{R} / \mathrm{C}$ rasio lebi $P 1$, lebih besar dibandingkan P0 dan P2. maka P1 dapat direkomendasikan dalam pengembangan usaha sapi potong.

$\mathrm{B} / \mathrm{C}$ rasio digunakan untuk mengetahui tingkat kelayakan usaha. $B / C$ rasio perlakuan $\mathrm{PO}(0,023)$ yang berarti setiap pengeluaran $\mathrm{Rp} 1000$ akan menghasilkan keuntungan $\mathrm{Rp}$ 23. P1 (0.025) yang berarti setiap pengeluaran $\mathrm{Rp} 1000$ akan menghasilkan keuntungan Rp 25. P2 (0.024) yang berarti setiap pengeluaran $\mathrm{Rp} 1000$ akan menghasilkan keuntungan Rp 24. Dilihat dari B/C rasio ketiga perlakuan menguntungkan, namun karena nilai $B / C$ rasio $P 1$ lebih besar dariP0 dan $P 2$ maka P1 direkomendasikan dalam pengembangan usaha sapi potong.

Titik impas atau Break Event Point (BEP) harga antara perlakuan P0 (Rp 58.650,-), P1 (Rp 58.516,-), P2 (Rp 58.598,-) artinya bahwa P0 dengan total produksi $886 \mathrm{~kg}$, pencapaian titik impas jika harga produk Rp 58.650,-/kg. P1 dengan total produksi $892 \mathrm{~kg}$, titik impas akan tercapai bila produk dijual dengan harga $\mathrm{Rp} 58.516,-/ \mathrm{kg}$ dan P2 dengan total produksi $1.082 \mathrm{~kg}$,titik impas akan tercapai bila produk dijual dengan harga $\mathrm{Rp} 58.598,-/ \mathrm{kg}$. Dilihat dari nilai titik impas atau BEP harga ketiga perlakuan efisien, namun yang lebih efisien dan direkomendasikan ialah

\section{SIMPULAN DAN SARAN}

\section{Simpulan}

1. Pengetahuan peternak meningkat dengan persentase 39,58 \% berada pada kriteri Cukup Efektif pada perlakuan P2 yakni dengan nilai BEP harga sebesar Rp 58.598,00. Titik impas atau Break Event Point (BEP) produksi: a). BEP produksi $P 0(866 \mathrm{~kg})$ dibandingkan dengan BEP harga sebesar Rp $58.650,00$ per $\mathrm{kg}$. Artinya produksi bobot badan sapi potong PO yang harus dicapai sebesar $(866 \mathrm{~kg})$ untuk mencapai titik impas dengan harga penjualan minimal $\mathrm{Rp} 58.650,00$. Jika peternak ingin mendapatkan keuntungan apabila dapat menjual ternaknya dengan harga jual > Rp $58.650,00$ per $\mathrm{kg}$ per ekor, jika harga jualnya Rp 60.000,00 per kg per ekor maka peternak telah mendapatkan keuntungan. $b$ ).

BEP produksi P1 (892 kg) dibandingkan dengan BEP harga sebesar Rp 58.516,00 per kg. Artinya produksi bobotbadan sapi potong $\mathrm{P} 1$ yang harus dicapai sebesar P1 (892 $\mathrm{kg}$ ) untuk mencapai titik impas dengan harga penjualan minimal $\mathrm{Rp}$ $58.516,00$. Jika peternak ingin mendapatkan keuntungan apabila dapat menjual ternaknya dengan harga jual > Rp 58.516.00 per kg per ekor, jika harga jualnya Rp 60.000,00 per kg per ekor maka peternak telah mendapatkan keuntungan. c). BEP produksi P2 (1.082 kg) dibanding dengan BEP harga sebesar Rp $58.598,00$ per $\mathrm{kg}$. Artinya produksi bobot badan sapi potong P2 yang harus dicapai sebesar 1.082 untuk mencapai titik impas dengan harga penjualan minimal $\mathrm{Rp} 58.598,00$. Jika peternak ingin untung harus dijual $>$ Rp 58.598,00 per kg per ekor, jika harga jualnya Rp 60.000,00 per kg per ekor maka peternak telah mendapatkan keuntungan.

atau Berhasil. Sikap peternak meningkat dengan persentase $37,50 \%$ berada pada Cukup Efektif atau Berhasil. Dan keterampilan peternak juga meningkat dengan persentase $41,39 \%$ berada pada kriteria 
Cukup Efektif atau Berhasil.

2. Penggunaan Aplikasi Sidik Peternakan dalam manajemen pemeliharaan sapi potong berpengaruh terhadap pendapatan peternak yakni sebesar Rp $1.571 .000,00$ dengan persentase hasil penilaian aspek GFP yakni sebesar $80 \%$.

\section{Saran}

Saran yang diberikan dari hasil penelitian ini yaitu untuk mendukung peningkatan kesejahteraan peternak dalam agribisnis penggemukan sapi potong yakni penulis merekomendasikan agar adanya tindaklanjut dari stakeholder terkait terhadap penerapan Good Farming Practice (GFP) melalui manajemen recording ternak yakni dengan mendesiminasikan aplikasi Sidik (Sistem Identifikasi dan Recording Ternak).

\section{DAFTAR PUSTAKA}

Badan Pusat Statistik. 2019. Volume Impor Daging Sapi di Indonesia. Jakarta: Badan PusatStatistik.
Badan Pusat Statistik. 2020. Tren Produksi Daging Sapi di Indonesia. Jakarta: Badan PusatStatistik.

Badan Pusat Statistik. 2013. Klasifikasi Kelas Umur Berdasarkan Angkatan Kerja Nasional. [online] http://bps.co.id [27 Juni 2021].

[BPP] Balai Penyuluhan Pertanian. 2020. Programa Penyuluhan Pertanian Kecamatan Panjalu. Ciamis: BPP.

[DAFRD] Department of Agriculture, Food and Rural Development. 2001. Good Farming Practice (GFP). Irlandia.

[DITJENPKH] Direktorat Jenderal Peternakan dan Kesehatan Hewan. 2016. Manajemen Agribisnis Penggemukan sapi potong. Jakarta.

Pane, I. 1993. Pemuliaan Ternak Sapi. Jakarta: Gramedia Pustaka Utama.

Padmowihardjo, 1996. Evaluasi Pelaksanaan Penyuluhan Pertanian. Jakarta: Universitas Terbuka. 